\title{
An Initial Evaluation of the Safety, Efficacy and Purity of VigRX, an Herbal Combination Formula, for the Enhancement of Male Sexual Health
}

\author{
Y. Smitasiri ${ }^{1}$, P. D'Souza ${ }^{2}$, J. Neal-Kababick ${ }^{3}$ and A.G. Schauss ${ }^{*}, 4$
}

${ }^{1}$ Mae Fah Luang University, Muang District, Chiang Rai 57100, Thailand

${ }^{2}$ Natural Remedies, Plot 5B, $19^{\text {th }}$ K. M Stone, Hosur Road, Bangalore 560 100, India

${ }^{3}$ Flora Research Laboratories, 1000 SE M Street, Grants Pass, Oregon 97526, USA

${ }^{4}$ Natural and Medicinal Products Research, AIBMR Life Sciences, Inc., 4117 S. Meridian, Puyallup, Washington 98373, USA

\begin{abstract}
An herbal combination formula, known as VigRX, has been studied for purity, safety and for efficacy in a Sprague-Dawley rat model. Two separate assays determined that VigRX was free from pharmaceutical adulterants, including phosphodiesterase type 5 (PDE-5) inhibitors and related analogues. An in vitro assay determined that VigRX is able to inhibit the enzyme Rho-kinase, suggesting a potential mechanism of action for this product. A 2-week (14-day) study in rats demonstrated a marked enhancement in sexual behavior, including decreased intromission and ejaculation latencies, and increased intromission, ejaculation and mounting frequencies, upon oral administration of $30 \mathrm{mg} / \mathrm{kg} / \mathrm{day}$. A longer 12 -week study using $15 \mathrm{mg} / \mathrm{kg} / \mathrm{day}$ showed only a decrease in ejaculation latency with respect to sexual behavior. In both studies, the treatment led to increased intracavernosal pressure, increased sperm concentration, and increased width of erect penis (and an increase in erect penile length in the 14-day study only). There was a statistically significant increase in blood testosterone levels in rats at the end of the 12-week study, which did not occur in the 14-day study. A non-dose dependent decrease in kidney and liver weights was found in the 14-day study that was not seen in the 12-week study, and neither study found any notable histopathological changes in any tissues studied. In conclusion, these preliminary results demonstrate safety and efficacy of VigRx for use in supporting male erectile function, and justify further investigation in these areas.
\end{abstract}

Keywords: Male erectile function, male sexual health, humans, active pharmaceutical ingredient, dietary supplement, herbal supplement, PDE-5 inhibitor, herbal medicine, Rho-kinase inhibition, penile intracavernosal pressure.

\section{INTRODUCTION}

Age-related decline in sexual function is a noted phenomenon worldwide. The prevalence in adult men has been estimated at 20-30\% [1,2]. Men aged 50-59 experienced three times more problems related to erections and low sexual desire than their 18-29 year old counterparts [2]. The pathophysiology of erectile dysfunction, a commonly experienced aspect of male sexual dysfunction, can include arteriogenic, neurogenic, endocrinologic, or psychogenic factors [3]. Multiple mechanisms may account for changes in these systems, including increased RhoA/Rho-kinase activity, impaired function of the nitric oxide (NO) and endothelial nitric-oxide synthase (eNOS) systems, and increased levels of inflammatory and prothrombotic vascular endothelial compounds [4-6].

Men have long sought remedies for declining sexual health. While prescription medications are often used, men are increasingly turning to herbal alternatives. The dietary supplement market includes a large number of products claiming to benefit men seeking enhancement of their

*Address correspondence to this author at the Natural and Medicinal Products Research, AIBMR Life Sciences, Inc., 4117 S. Meridian, Puyallup, Washington 98373, USA; Tel: +1-253-286-2888; Fax: +1-253-286-2451; E-mail: alex@aibmr.com erectile function, sexual health and performance. While the consumer may assume these "natural" products are safe, this category of dietary supplements is marred with numerous reports of adulteration with active pharmaceutical ingredients (APIs) [7]. Some APIs commonly discovered in these misleading supplements include phosphodiesterase (PDE-5) inhibitors such as sildenafil $\left(\right.$ Viagra $\left.^{\circledR}\right)$, vardenafil $\left(\right.$ Levitra $\left.^{\circledR}\right)$, and tadalafil $\left(\mathrm{Cialis}^{\circledR}\right.$ ), or their analogues. Because these prescription drugs are used as effective treatments for erectile dysfunction, their inclusion in herbal formulas may enhance the efficacy of these formulas, misleading consumers to attribute positive results to the listed combination of vitamins and herbs in the ingredients rather than the effect of the pharmaceutical adulterant. Furthermore, not disclosing the presence of the API adulterants on the labeling of these products puts consumers at considerable risk, including exposure to side effects such as flushing, headaches, palpitation, nasal congestion, and visual disturbances $[8,9]$. Of even greater concern is the possibility of these pharmaceutical adulterants interacting with other medications the consumer could be taking [10]. For instance, the combination of nitroglycerine and PDE-5 inhibitors or their analogues can dangerously lower blood pressure. This is of particular relevance because the population that is prescribed nitrates also commonly suffers from erectile dysfunction. While doctors generally warn patients on nitrates against taking pharmaceutical 
PDE-5 inhibitors, these individuals may turn to dietary supplements as "natural" alternatives to treating their erectile dysfunction [7,11].

Unfortunately, there is evidence that this illegal practice of including undisclosed APIs in dietary supplements is widespread [11-13]. This adulteration can occur at any step of the manufacturing process, and may be unknown to the companies who are marketing and selling the product. Therefore, conscientious dietary supplement manufacturers should test every batch of finished products for APIs to assure no adulteration took place during any step of manufacturing. This serves to ensure the quality and identity of the product being consumed as well as heighten the potential level of safety of the formulation.

Long before the advent of synthetic pharmaceuticals for the treatment of sexual dysfunction, herbal medications have been used as sexual health supportive agents in diverse cultures throughout the world. While the traditional use of such plants is extensive, recent scientific investigations into individual herbs and combination formulas have yielded important positive data in terms of the ability of botanicals to support sexual wellness and the erectile process. There are many medicinal plants that have been reported to possess aphrodisiac effects, such as Muira Puama (Ptychopetalum spp.) root and Catuaba (Trichilia catigua) bark [13]. Recent research has demonstrated increased sexual activity in rats after oral administration of an extract of Ginkgo biloba [14]. Other medicinal plants, such as Panax ginseng root, are thought to enhance circulation through nitric oxide mediated vasodilation [15]. Hawthorn (Crataegus spp.) berry is also purported to possess vasodilatory effects [16,17]. Ginkgo biloba leaf and Panax ginseng root are known to have antioxidant properties [15]. These and other physiological actions highlight the potential of botanicals to support and/or enhance erectile function.

Penile erection occurs in response to cavernous smooth muscle relaxation, increased blood flow to the penis, and restriction of venous outflow. These events are regulated by a spinal reflex relying on visual, imaginative, and olfactory stimuli generated within the central nervous system (CNS) and on tactile stimuli to the penis. Pharmaceutical or botanical drugs can have a stimulatory or inhibitory effect either on the nerves regulating this reflex or directly on the cavernous smooth muscle within the penis. A balance between contractile and relaxant factors governs penile flaccidity/rigidity.

Of the numerous biochemical reactions involved in regulating penile smooth muscle tone, the phosphorylation state of myosin fibrils is of central importance. When phosphorylated, myosin induces the contraction of smooth muscle, leading to vasoconstriction and penile detumescence. The opposite effect is seen when myosin is dephosphorylated. The phosphorylation state of myosin is controlled by the enzyme myosin phosphatase, which is active in its dephosphorylated form. Rho-kinase is an enzyme that phosphorylates myosin phosphatase, thereby inactivating it. Inhibition of Rho-kinase thus keeps myosin phosphatase in an active state, leading to the dephosphorylation of myosin and consequently the relaxation of smooth muscle. Smooth muscle relaxation in turn results in increased blood flow and turgidity of penile tissue [18].
Thus, agents that inhibit the Rho-kinase enzyme may have a direct effect on erectile function. This has been demonstrated in vivo following the administration of the selective Rho-kinase inhibitor Y-27632 to rats [19]. Pharmaceuticals and botanicals alike are known to possess Rho-kinase inhibitory activity as a means of facilitating the erectile process. Assays such as the one measuring Rho-kinase inhibition serve to elucidate potential mechanisms of action whereby promising compounds could have beneficial effects on a particular physiological function.

Once an in vitro evaluation has yielded insights into a possible or likely mechanism of action, a logical next step in the progression of research is to evaluate the efficacy of a product in a valid animal model. The rat has been established as a suitable animal model for the study of penile erection [20], and has been used to study the effects of a number of medicinal plants on sexual behavior [21-25]. Research in rats can yield important preliminary information regarding the effects of a formula on various parameters associated with male sexual function.

While many marketers of herbal sexual health aids cite historical precedent as their evidence for efficacy, the need for scientific investigation into the validity of these claims is necessary. In vitro assays, animal studies and ultimately human clinical trials can help elucidate possible mechanisms of action, establish safety, and investigate the efficacy of dietary supplement products.

This report summarizes initial research directions investigating the quality, safety, efficacy and potential mechanisms of action of VigRX, an herbal formulation containing a variety of botanical ingredients with purported aphrodisiac properties based on traditional use.

Research summarized here includes the effects of VigRX on inhibition of Rho-kinase in vitro, and the evaluation of its effect on erectile function, tumescent penis size, and sex drive in the male rat. In addition, investigations were conducted to assess the purity of VigRX by analyzing the batch used in the aforementioned studies for the presence or absence of pharmaceutical adulterants.

\section{MATERIALS AND METHODS}

\subsection{Test Article}

All five of the studies described used VigRX (Leading Edge Herbals, Greeley, Colorado, USA, Lot \#4242) as the test article. VigRX is made up of a proprietary blend of Panax ginseng root, Saw palmetto berry powder (Serenoa repens), Gingko biloba leaf powder, Hawthorn berry (Crataegus laevigata), Muira Puama bark extract 4:1 (Ptychopetalum olacoides), Catuaba bark extract 4:1 powder (Erythroxylum catuaba), Cuscuta seed extract 4:1 (Cuscuta chinensis), and Epimedium sagittatum extract 20:1.

\subsection{Assays for Pharmaceutical Adulteration}

\subsubsection{Assay for PDE-5 Inhibitor Analogues}

VigRX was tested for the presence of PDE-5 inhibitors and their analogues by Flora Research Laboratories (Grants Pass, Oregon, USA). Samples were prepared by mixing the contents of $20 \mathrm{VigRX}$ capsules. The material was then sieved via a 40 mesh sieve and blended on lab paper. 0.5 grams of the sample was then weighed into a $100 \mathrm{~mL}$ volu- 
metric flask and $80 \mathrm{~mL}$ of a 1:1 mixture of acetonitrile (Chromasolve $\AA$, Sigma-Aldrich $\AA$ ) and water (Type 1, generated in house using Easy Pure $\AA$, Barnstead, Dubuque, Iowa, USA) was added to the flask and swirled to wet the contents. The flask was then shaken for 15 minutes on a Burrell Wrist Action ${ }^{\circledR}$ shaker followed by sonication at room temperature for 15 minutes. After allowing the contents to cool to room temperature, the flask was diluted to volume, mixed and approximately $10 \mathrm{~mL}$ was transferred to a $15 \mathrm{~mL}$ BD Falcon polypropylene centrifuge tube (PPCT). This aliquot was centrifuged at $3500 \mathrm{rpm}$ for 15 minutes (Beckman GS-6). The supernatant was syringe filtered via a $0.45 \mathrm{mi}-$ cron $25 \mathrm{~mm}$ diameter polytetrafluoroethylene syringe filter, discarding the first few $\mathrm{mL}$ and collecting the remaining sample in an amber screw cap vial for analysis. A second aliquot of the test sample was placed into a second $15 \mathrm{~mL}$ PPCT as above and spiked with 100 ppm sildenafil for quality control purposes.

For HPLC analysis, an aliquot was transferred to an amber HPLC autosampler vial with snap cap (National Scientific). For HPLC-PDA-MSn analysis, $25 \mu \mathrm{L}$ was transferred to the same type of vial and diluted to $1 \mathrm{~mL}$ using the $50 \%$ acetonitrile extraction solvent.

Two separate screening methods were utilized to examine the product for PDE-5 inhibitors. Initially, analysis was carried out using an HP100 HPLC system with a diode array detector (Agilent). The separation was performed using a Zorbax Eclipse XDB-Phenyl $4.5 \times 1505 \mu \mathrm{m}$ at $40^{\circ} \mathrm{C}$. The mobile phase was a gradient consisting of $10 \mathrm{mM}$ ammonium acetate (Fluka) in water (A) and acetonitrile (B). The gradient went from $20 \%$ B to $80 \%$ B in 20 minutes. Detection was carried out at $230 \mathrm{~nm}$ and $290 \mathrm{~nm}$ and peak spectra were collected as well. This method elutes the bulk of the botanical phytochemicals early near the void volume allowing the PDE-5 inhibitor drugs to elute later in the middle or end of the run. Spectra were acquired for the prescription PDE-5 inhibitors and sildenafil was used as a qualitative spike to determine run performance and chromatogram alignment. Spectra were compared to the parent approved prescription PDE-5 inhibitors and to published spectra for known analogues. Two criteria were used to establish adulteration. First, in almost all adulterated products tested, there was a major peak eluting in the PDE-5 inhibitor window indicating a pharmaceutical dosage level. The second criterion was the presence of a spectra matching or related to the known PDE5 inhibitors and their analogues.

A second analysis was carried out using a Varian 500 Ion-Trap LC-MS system equipped with TurboDDS (Varian). The system was also equipped with a Varian 335 Prostar PDA Detector to collect PDA spectra during the runs. The column used was a Varian Pursuit XRs 3u C-18 150x2 at $35^{\circ} \mathrm{C}$. The mobile phase was a gradient consisting of Type 1 water containing $0.1 \%$ formic acid (EMD Chemicals) (A) and acetonitrile containing $0.1 \%$ formic acid (B). The gradient was $20 \%$ B to $80 \%$ B over 20 minutes. The separation allowed for phytochemical constituents to elute across the run time and thus required careful analysis of the PDA spectra and MS data. The TurboDDS mode was set to acquire $\mathrm{MS} / \mathrm{MS}$ spectra on the 3 largest ions detected in a given microscan. The largest product ion in any given MS/MS spectra was further fragmented to provide MS3 spectra. The instrument was operated in $\mathrm{ESI}(+)$ mode.
Following data acquisition, the data were evaluated in the software with MS/MS ion trigger masses sorted by weight. If any masses were identified that matched up to the PDE-5 inhibitors or known analogues (based on the FDA FCC Compound List), the ion was selected and the product spectrum ions were evaluated against the list. If all ions were present in the relative ratios, the compound was considered preliminary positive. A second HPLC-MS/MS run was set up for that exact compound and used for confirmation spectra in order to obtain an enhanced spectra for the exact compound. If this too was positive, then the sample was determined to be adulterated with that compound.

\subsubsection{Assay for Active Pharmaceutical Ingredients}

A novel assay for inspecting 180 APIs, including steroids, CNS stimulants, hormones, and narcotics, was performed by General Standard Laboratory (Taipei, Taiwan) using HPLC.

The standard solution was prepared by weighing $8 \mathrm{mg}$ of each standard API and dissolving it in $4 \mathrm{~mL}$ of methanol (ChromAR ${ }^{\circledR}$, LC grade, Mallinckrodt Chemicals) to make stock solution with the concentration of $2.0 \mathrm{mg} / \mathrm{mL}$. The stock solution was further diluted with $100 \mathrm{X}$ methanol to reach a concentration of $0.02 \mathrm{mg} / \mathrm{ml}$. A quality control standard was also prepared by weighing $8 \mathrm{mg}$ of each standard pharmaceutical ingredient and dissolving it in $4 \mathrm{~mL}$ of methanol to reach the concentration of $2.0 \mathrm{mg} / \mathrm{mL}$. Quality control testing using a standard API solution was performed following every tenth sample tested, in order to measure the change in the retention time of the HPLC apparatus (Hitachi D-700 interface, L-7100 pump, L-7200 autosampler, L-7455 diode array detector).

To prepare the test material, the content of ten VigRX capsules was emptied and well mixed. Subsequently, $0.5 \mathrm{~g}$ of the sample was measured, added to $5.0 \mathrm{~mL}$ of methanol and vortexed. The sample solution was then sonicated for 15 minutes and centrifuged for 10 minutes at $3000 \mathrm{rpm}$. Liquid from the upper layer of the test tube was collected and diluted with $5 \mathrm{X}$ methanol.

The analysis column used was Supelco Ascentis C18 $(5 \mu \mathrm{m} 25 \mathrm{~cm} \times 4.6 \mathrm{~mm})$ (Sigma-Aldrich $\AA)$. The injection volume was $20 \mu \mathrm{L}$. Data acquisition was preformed by Hitachi D-7000 HPLC System Management (Suzuka, Japan).

Identification of pharmaceutical adulterants present in the sample was made by comparing the UV spectrum of each sample peak above 0.05 absorbance units at $200 \mathrm{~nm}$ with the spectral library of the standard APIs. A second validation was performed when the retention time of sample peaks differed by $\pm 10 \%$ and the similarity of the sample spectrum with the standard library reached above $92 \%$.

The criteria for positive identification of pharmaceutical adulteration was: a) the result showed only peaks of the suspicious adulterants; b) the concentration of a suspicious peak was increased; and, c) the similarity of the UV spectrum between a suspicious peak and standard library exceeded $95 \%$.

\subsection{Rho-Kinase II Enzyme Inhibition Assay}

The Rho-kinase enzyme inhibition assay was conducted by Natural Remedies (Bangalore, India). This assay is based 
on ELISA and operates according to the following principles. Plates are pre-coated with a substrate corresponding to the recombinant $\mathrm{C}$ terminus of the myosin-binding subunit (MBS) of myosin phosphatase. The threonine residue of the MBS is phosphorylated by members of the myotonic dystrophy protein kinase family, including Rho-kinase. The detector antibody AF20 specifically detects only the phosphorylated form of threonine-696 on MBS. The amount of phosphorylated substrate is measured by binding it with an antiphospho-MBS threonine-696 specific antibody conjugated with horseradish peroxidase, which then catalyzed the conversion of the chromogenic substrate tetramethylbenzidine from a colorless solution to a blue solution (or yellow after addition of stopping solution). The color is quantified by spectrophotometry and reflects the relative amount of Rhokinase activity.

A Rho-kinase assay kit CY-1160 (Cyclex Co. Ltd., Nagano, Japan) was used. The components of the kit included microplate-wells coated with recombinant MBS C terminus, 10X wash buffer, kinase buffer, 20X ATP, HRP conjugated detection antibody, substrate solution, stop solution, Rhokinase II (CY-E 1160-1, Cyclex Co.), and Rho-kinase specific inhibitor Y-27632 (Calbiochem, cat. no. 688001).

Two grams of VigRX were sonicated for 8 minutes in 20 $\mathrm{mL}$ of methanol. Ultra-pure water was added to attain a total volume of $100 \mathrm{~mL}$ of solution. The solution was filtered and the resulting filtrate was used for the assay. It was found that the VigRX capsule content was $19.3 \%$ soluble $(385.94 \mathrm{mg}$ was soluble out of $2000 \mathrm{mg}$ ). For calculation purposes, the stock solution was considered to be $20 \mathrm{mg} / \mathrm{mL}$.

The assay was carried out as follows: a total reaction mixture of $100 \mu \mathrm{L}$, containing kinase reaction buffer, varying concentrations of VigRX (125, 250, 500, 1000, and 2000 $\mu \mathrm{g} / \mathrm{mL}$ ) or Y-27632 (the positive control), 10 munits of Rhokinase II enzyme, and $100 \mu \mathrm{M}$ of ATP, was combined and incubated at $30^{\circ} \mathrm{C}$ for 30 minutes in a substrate coated plate. Following incubation, the contents of the wells were discarded and washed $200 \mu \mathrm{L} \mathrm{X} 5$ times with $1 \mathrm{X}$ wash buffer. $100 \mu \mathrm{L}$ of HRP conjugated detection antibody was added and incubated at $25^{\circ} \mathrm{C}$ for 60 minutes. The contents were discarded and the wells were washed $200 \mu \mathrm{L}$ X 5 times with $1 \mathrm{X}$ wash buffer. $100 \mu \mathrm{L}$ of substrate solution was added and incubated at $25^{\circ} \mathrm{C}$ for 15 minutes. Finally $100 \mu \mathrm{L}$ of stop solution was added and the absorbance was measured at 450 $\mathrm{nm}$ in a spectrophotometer (Versamax microplate reader, Molecular Devices). The \% inhibition was calculated as follows: $\%$ inhibition $=\{[$ Absorbance of control - Absorbance of test] / Absorbance of control $\}$ X 100. The $\mathrm{IC}_{50}$ was calculated using log-probit analysis.

\subsection{Aphrodisiac Activity Studies in Male Sprague- Dawley Rats}

\subsubsection{Test Animals}

Sprague-Dawley adult male (250-280 g) and female rats (200-240 g) were used in this study. All of the rats were sourced from the National Laboratory Animal Center at Mahidol University, Nakhon Pathom Province, Thailand. They were transferred to Mae Fah Luang University, Chiang Rai, Thailand, by air and reared in the Laboratory Animal House in a temperature-controlled room (approximately $24 \pm 1^{\circ} \mathrm{C}$ ) with proper ventilation and a daily light-dark cycle of 12 hours. All of the rats were fed rodent feed Number 082 (Pokkapan Animal Feed Co. Ltd.). Water was provided to the rats ad libitum during the entire period of the study. The university's board authorized to regulate animal experiments approved all experiments conducted.

\subsubsection{Preparation of Test Material}

The contents of the VigRX capsules (Lot \#4242) were mixed with distilled water and prepared into two dosages to be administered at 15 and $30 \mathrm{mg} / \mathrm{kg} /$ day. These dosages were chosen to allometrically reflect the current recommended doses of VigRX in adult human males ( 2 or 4 capsules per day), using an average body weight of $70 \mathrm{~kg}$.

\subsubsection{4-Day Study in Sprague-Dawley Rats}

The rats were divided into 3 groups (10 rats/group): Group 1 received $1 \mathrm{~mL} /$ day of distilled water administered orally for 14 consecutive days. Group 2 and 3 were similar to the control group, but received VigRX at either 15 or 30 $\mathrm{mg} / \mathrm{kg}$ /day respectively for 14 consecutive days. Each rat was weighed every three days until the test was completed on Day 14. On Day 14, between 7-9 p.m., the sexual behavior of each adult male rat exposed to a female rat in-estrus was observed. (Female rats were induced into estrus with subcutaneous doses of estradiol benzoate and progesterone as described by Islam et al. [26]). Each adult male rat was placed into an individual glass cupboard and a dim light was turned on for 5 minutes prior to the start of observation. Subsequently, the female rats in estrus were caged with male rats at a ratio of $1: 1$. Sexual behavior of the male rat was observed and recorded with a video recorder for 30 minutes. The latency and frequency of mounting, intromission and ejaculation were then assessed. Statistical analysis was performed using ANOVA and LSD.

On Day 15, after weighing, the erect penis was measured per the following protocol. Each rat was put in supine position, the anterior portion of its body was inserted into a plastic cylinder, and the trunk, limbs and tail were restrained. The penile sheath was retracted to expose the glans penis, and this position was maintained using forceps. Light tactile stimulation was applied to the base of the glans penis for 1-2 minutes until penis became fully erect. The width of the base of the glans penis and the length between the tip of glans penis and base of penis were then measured. Subsequently, the rat was anesthetized with an intraperitoneal injection of Nembutal (pentobarbital), at which point the intracavernous pressure (ICP) was recorded using the method described by Tocharus et al. [27]. Blood was then collected via cardiac puncture and testosterone levels were measured using electrochemical luminescence. The animals were euthanized and the penis, testes, epididymis, prostate gland, seminal vesicle, pituitary gland, adrenal gland, liver, kidney and spleen were removed and weighed (Mettler Toledo AB 204-S). After weighing the epididymis, the cauda epididymis was removed and the sperm concentration was counted using a Neubauer hemacytometer. A histopathological examination was conducted on all organs that demonstrated a weight change.

\subsubsection{2-Week Study in Sprague-Dawley Rat}

The rats were divided into two groups consisting of twelve rats each. Group 1 served as the control and received 
$1 \mathrm{~mL}$ of distilled water administered orally each day for 84 consecutive days (12 weeks). Group 2 received VigRX administered orally at the dosage of $15 \mathrm{mg} / \mathrm{kg} / \mathrm{day}$ for 84 consecutive days (12 weeks). Each rat was weighed every seven days until the test was completed. On Day 28 (4 weeks), 56 ( 8 weeks) and 84 (12 weeks), between 7-9 p.m., the sexual behavior of each adult male rat exposed to a female rat in estrus was observed in the same manner as in the 14-day study reported above. Statistical analysis was performed using ANOVA and LSD.

On Day 85, after weighing, erect penile size was measured as in the 14-day study. The rats were then anaesthetized and the intracavernous pressure (ICP) was recorded. Blood was collected via cardiac puncture to measure testosterone levels (using electrochemical luminescence), and clinical blood chemistry parameters including aspartate aminotransferase (AST), alanine aminotransferase (ALT), alkaline phosphatase, creatinine, blood urea nitrogen (BUN), cholesterol, triglycerides, total protein, albumin, and glucose were assessed. The animals were subsequently euthanized and the penis, testes, epididymis, prostate gland, seminal vesicle, pituitary gland, adrenal gland, liver, kidney and spleen were removed and weighed. After weighing, the epididymis and the cauda epididymis were removed and the sperm concentration was counted using a Neubauer hemacytometer in the same manner as the 14-day study. The liver, kidney and testes were sectioned for histopathological studies. The liver was specifically examined for fatty degeneration, hepatocyte megalocytosis, lymphoid aggregated periportal area, bile duct proliferation and peliosis hepatitis. The kidneys were specifically examined for multifocal tubular cysts, tubular casts and tubulonephrosis. The testes were specifically examined for signs of interstitial edema, seminiferous tubule degeneration and congestion. All collected data was statistically analyzed using ANOVA and LSD.

\section{RESULTS}

\subsection{Assays for Product Adulteration with PDE-5 Inhibi- tor Analogues and APIs}

VigRX was found to contain no detectable levels of known PDE-5 inhibitors including sildenafil, tadalafil, vardenafil or related analogues known at the time of the study (Table 1).

A separate assay determined that VigRX was free from adulteration with any of the 180 tested APIs representing the following 19 drug categories: steroids, diuretics, gastrointestinal drugs, CNS stimulants, local anesthetics, antilipemic drugs, antibiotics, CNS depressants, muscle relaxants, antigout drugs, hormone drugs, antidiabetics, analgesics/NSAIDs, bronchodilators, abused drugs, narcotics, antihistamines, cardiovascular drugs, and antitussives/expectorants.

\subsection{Rho-Kinase II Enzyme Inhibition Assay}

VigRX exhibited concentration-dependant inhibitory effects in the Rho-kinase assay with a fifty percent inhibitory concentration $\left(\mathrm{IC}_{50}\right)$ of $1673.18 \mu \mathrm{g} / \mathrm{mL}$ (95\% confidence interval of $1216.28-2710.01 \mu \mathrm{g} / \mathrm{mL}$ ) (Table 2).
Table 1. List of PDE-5 Inhibitor Drugs and Known Analogues Screened for $($ Detection Limit $=100$ ppm)

\begin{tabular}{|l|l|}
\hline PDE-5 Inhibitor & Result \\
\hline \hline Acetildenafil & ND \\
\hline Aminotadalafil & ND \\
\hline Benzamidenafil & ND \\
\hline Dimethyl sildenafil (aildenafil) & ND \\
\hline Dimethyl sildenafil thione (sulfoaildenafil) & ND \\
\hline Homosildenafil & ND \\
\hline Hydroxyacetildenafil & ND \\
\hline Hydroxyhomosildenafil & ND \\
\hline Noracetildenafil & ND \\
\hline Piperadino acetildenafil & ND \\
\hline Piperadino vardenafil & ND \\
\hline Sildenafil & ND \\
\hline Sildenafil thione (sulfosildenafil) & ND \\
\hline Sildenafil thione (sulfohomosildenafil) & ND \\
\hline Tadalafil & ND \\
\hline Vardenafil & ND \\
\hline ND=not detected. & \\
\hline
\end{tabular}

\subsection{Aphrodisiac Activity Study in Male Sprague-Dawley Rats}

\subsubsection{4-Day Study}

Male rats fed $\operatorname{VigRX}$ at a dose of $30 \mathrm{mg} / \mathrm{kg} /$ day for 14 consecutive days experienced a significant decrease in intromission latency and ejaculation latency and an increase in intromission frequency, ejaculation frequency and mounting frequency as compared to the control group $(p<0.05)$ (Table 3). Rats fed VigRX at $30 \mathrm{mg} / \mathrm{kg} / \mathrm{day}$ also experienced a statistically significant increase in the length and width of their erect penis when compared with the control group $(p<0.05)$, whereas the rats fed $\operatorname{VigRX}$ at $15 \mathrm{mg} / \mathrm{kg} /$ day experienced an increase only in the length of the erect penis $(p<0.05)$. Both dosages of VigRX were shown to significantly increase the intracavernosal pressure (ICP) compared to control group ( $p$ $<0.001)$. An increase in sperm concentration was noted only in the group treated with VigRX at $30 \mathrm{mg} / \mathrm{kg} / \mathrm{day}(p<0.05)$. However, no significant difference was seen in the testosterone level in either the VigRX treated groups or the control group.

There was no significant difference between the body weight gained of the VigRX-treated groups and the control group (Table 4). The organ weights of both treatment groups did not significantly differ from the control group after 14 days, with the exception of a decrease in liver weight experienced by both the 15 and $30 \mathrm{mg} / \mathrm{kg} /$ day treatment groups and a decrease in kidney weight experienced only by the 15 $\mathrm{mg} / \mathrm{kg} /$ day group $(p<0.01)$. Neither of these decreases was 
Table 2. Rho-Kinase II Inhibition Assay

\begin{tabular}{|c|c|c|c|}
\hline & $\begin{array}{c}\text { Concentration } \\
(\mu \mathrm{g} / \mathrm{mL})\end{array}$ & $\begin{array}{l}\text { Percent Inhibition }(\text { mean } \pm \text { SD) } \\
\mathbf{n}=\mathbf{2}\end{array}$ & $\begin{array}{c}\mathrm{IC}_{50} \text { as } \mu \mathrm{g} / \mathrm{mL} \\
(95 \% \text { confidence interval) }\end{array}$ \\
\hline \multirow{3}{*}{$\begin{array}{l}\text { Rho-kinase specific } \\
\text { inhibitor (Y-27632) }\end{array}$} & 0.0032 & $4.06 \pm 0.52$ & \multirow{3}{*}{$\begin{array}{c}0.20 \\
(0.13-0.319)\end{array}$} \\
\hline & 0.032 & $33.40 \pm 1.64$ & \\
\hline & 0.32 & $57.22 \pm 0$ & \\
\hline \multirow{4}{*}{ VigRX } & 125 & $11.5 \pm 0.9$ & \multirow{4}{*}{$\begin{array}{c}1673.18 \\
(1216.28-2710.01)\end{array}$} \\
\hline & 250 & $18.38 \pm 1.73$ & \\
\hline & 500 & $29.98 \pm 0.82$ & \\
\hline & 1000 & $35.36 \pm 2.86$ & \\
\hline
\end{tabular}

Table 3. Sexual Behavior in Rat Studies

\begin{tabular}{|c|c|c|c|c|c|c|}
\hline \multirow{2}{*}{\multicolumn{2}{|c|}{ Sexual Behavior Paramater }} & \multicolumn{3}{|c|}{$\begin{array}{c}\text { 2-week (14-day) study } \\
\text { n=10 per group }\end{array}$} & \multicolumn{2}{|c|}{$\begin{array}{l}\text { 12-week study } \\
\text { n=12 per group }\end{array}$} \\
\hline & & \multirow{2}{*}{$\begin{array}{c}\text { Control } \\
67.8 \pm 36.6\end{array}$} & \multirow{2}{*}{$\begin{array}{c}\begin{array}{c}\text { VigRX } \\
\mathbf{1 5} \mathbf{~} \mathbf{~ g} / \mathbf{k g} / \mathbf{d a y}\end{array} \\
48 \pm 25.8\end{array}$} & \multirow{2}{*}{$\begin{array}{c}\begin{array}{c}\text { VigRX } \\
\mathbf{3 0} \mathbf{~} \mathbf{m g} / \mathbf{k g} / \mathbf{d a y}\end{array} \\
39.6 \pm 22.2\end{array}$} & \multirow{2}{*}{$\begin{array}{c}\text { Control } \\
126.25 \pm 40.93\end{array}$} & \multirow{2}{*}{$\begin{array}{c}\text { VigRX } \\
\mathbf{1 5} \mathbf{~} \mathbf{m g} / \mathbf{k g} / \text { day }\end{array}$} \\
\hline Latency & Mount $^{\mathrm{a}}$ & & & & & \\
\hline (seconds) & Intromission $^{\mathrm{b}}$ & $345.6 \pm 159.6$ & $229.2 \pm 94.2$ & $109.2 \pm 32.4 * *$ & $228.67 \pm 55.58$ & $231.75 \pm 87.13$ \\
\hline & Ejaculation $^{\mathrm{c}}$ & $954 \pm 321$ & $736.8 \pm 169.2$ & $539.4 \pm 142.2^{*}$ & $1730.00 \pm 49.87$ & $1474.00 \pm 149.17^{*}$ \\
\hline \multirow{3}{*}{$\begin{array}{l}\text { Frequency } \\
\text { (number of } \\
\text { times) }\end{array}$} & Mount $^{\mathrm{d}}$ & $34.80 \pm 8.47$ & $43.00 \pm 10.63$ & $50.57 \pm 10.28^{*}$ & $47.00 \pm 5.23$ & $37.60 \pm 9.58$ \\
\hline & Intromission $^{\mathrm{e}}$ & $19.00 \pm 8.12$ & $28.20 \pm 6.69$ & $35.71 \pm 10.13 * *$ & $27.00 \pm 9.56$ & $23.00 \pm 5.61$ \\
\hline & Ejaculation $^{\mathrm{f}}$ & $1.25 \pm 0.50$ & $2.75 \pm 1.50$ & $3.14 \pm 1.21 *$ & $1.00 \pm 0.00$ & $1.50 \pm 1.00$ \\
\hline \multirow{2}{*}{$\begin{array}{l}\text { Erect Penile } \\
\text { Size (mm.) }\end{array}$} & Width & $5.60 \pm 0.44$ & $5.80 \pm 0.45$ & $6.03 \pm 0.21 *$ & $5.81 \pm 0.40$ & $6.38 \pm 0.43 * *$ \\
\hline & Length & $10.31 \pm 0.80$ & $11.38 \pm 1.16^{*}$ & $12.57 \pm 1.12 * *$ & $11.36 \pm 1.11$ & $12.00 \pm 0.84$ \\
\hline \multicolumn{2}{|c|}{ Intracavernous pressure (mmHg) } & $49.70 \pm 2.49$ & $70.68 \pm 3.66^{* * *}$ & $83.56 \pm 5.33 * * *$ & $58.08 \pm 4.60$ & $85.75 \pm 6.14 *$ \\
\hline \multicolumn{2}{|c|}{ Sperm Density $\left(\times 10^{7} / \mathrm{mL}\right)$} & $21.00 \pm 2.95$ & $22.67 \pm 1.64$ & $24.05 \pm 3.76^{*}$ & $20.41 \pm 3.30$ & $24.57 \pm 3.64 * *$ \\
\hline
\end{tabular}

Values are mean $\pm \mathrm{SD}$

$* p<0.05 * * p<0.01 * * * p<0.001$

${ }^{a}$ Time interval between introduction of the female and first mount by the male.

${ }^{\mathrm{b}}$ Time interval between introduction of the female and first intromission by the male.

${ }^{\mathrm{c}}$ Time interval between introduction of the female and first ejaculation by the male.

${ }^{\mathrm{d}}$ Number of mounts with intromission from the time of introduction of the female until ejaculation.

${ }^{e}$ Number of intromissions from the time of introduction of the female until ejaculation.

${ }^{\mathrm{f}}$ Number of ejaculations (characterized by longer, deeper pelvic thrusting and slow dismount followed by a period of inactivity).

observed to be dose-dependent, and histopathological examination of the liver and kidney revealed no differences between treatment and control groups.

\subsubsection{2-Week Study}

The ejaculation latency of the rats treated with a VigRX dose of $15 \mathrm{mg} / \mathrm{kg} /$ day was significantly less than the control group after 12 weeks of treatment $(p<0.05)$ (Table 3). No other significant differences in sexual behavior were noted in male rats treated with VigRX for 4,8 or 12 weeks when compared to controls.
The VigRX-treated animals in this study experienced significant increases in sperm concentration, width of the erect penis, and intracavernosal pressure compared to control animals. Mean sperm concentration values after 12 weeks were $24.57 \pm 3.64 \times 10^{7} / \mathrm{mL}$ in the VigRX treated animals while the values were $20.41 \pm 3.30 \times 10^{7} / \mathrm{mL}$ in the control group $(p<0.01)$. The mean values for erect penile width were $6.38 \pm 0.43 \mathrm{~mm}$ in the VigRX treated group and 5.81 $\pm 0.40 \mathrm{~mm}$ in the control group ( $p<0.01$ ). The mean intracavernosal pressure measurement in the VigRX treated 
Table 4. Body and Organ Weights in Rat Studies

\begin{tabular}{|c|c|c|c|c|c|}
\hline & \multicolumn{3}{|c|}{$\begin{array}{l}\text { 2-week (14-day) study } \\
\text { n=10 per group }\end{array}$} & \multicolumn{2}{|c|}{$\begin{array}{l}\text { 12-week study } \\
n=12 \text { per group }\end{array}$} \\
\hline & Control & $\begin{array}{c}\text { VigRX } \\
15 \mathrm{mg} / \mathrm{kg} / \text { day }\end{array}$ & $\begin{array}{c}\text { VigRX } \\
30 \mathrm{mg} / \mathrm{kg} / \mathrm{day}\end{array}$ & Control & $\begin{array}{c}\text { VigRX } \\
15 \mathrm{mg} / \mathrm{kg} / \text { day }\end{array}$ \\
\hline Body weight (g) & $398.20 \pm 19.59$ & $393.40 \pm 16.90$ & $392.30 \pm 11.53$ & $488.00 \pm 43.63$ & $467.67 \pm 34.32$ \\
\hline Penis (mg\%) & $71.00 \pm 11.81$ & $75.82 \pm 9.86$ & $71.22 \pm 5.79$ & $66.66 \pm 9.65$ & $71.81 \pm 7.86$ \\
\hline Testes $(\mathrm{mg} \%)$ & $928.29 \pm 60.25$ & $934.52 \pm 51.29$ & $929.01 \pm 18.13$ & $814.61 \pm 89.97$ & $811.84 \pm 107.07$ \\
\hline Epididymis (mg\%) & $256.99 \pm 14.53$ & $265.30 \pm 16.84$ & $250.50 \pm 10.91$ & $281.01 \pm 23.14$ & $281.01 \pm 23.14$ \\
\hline Seminal vesicle (mg\%) & $313.30 \pm 47.27$ & $340.56 \pm 45.77$ & $332.02 \pm 40.94$ & $253.27 \pm 73.08$ & $271.08 \pm 74.73$ \\
\hline Prostate gland (mg\%) & $96.13 \pm 18.68$ & $106.30 \pm 14.66$ & $110.37 \pm 25.25$ & $71.72 \pm 16.07$ & $84.62 \pm 17.80$ \\
\hline Liver (mg\%) & $4010.33 \pm 498.80$ & $3512.82 \pm 197.19^{* *}$ & $3552.43 \pm 220.40^{* *}$ & $3271.31 \pm 167.72$ & $3268.14 \pm 180.61$ \\
\hline Kidney (mg\%) & $710.38 \pm 38.34$ & $664.68 \pm 24.80 * *$ & $685.69 \pm 27.64$ & $585.11 \pm 34.35$ & $607.48 \pm 36.96$ \\
\hline Adrenal gland (mg\%) & $16.08 \pm 1.77$ & $15.53 \pm 1.47$ & $14.98 \pm 1.42$ & $12.21 \pm 1.03$ & $12.35 \pm 1.60$ \\
\hline Spleen (mg\%) & $232.80 \pm 22.06$ & $233.01 \pm 11.42$ & $247.74 \pm 25.64$ & $198.17 \pm 15.22$ & $196.05 \pm 17.24$ \\
\hline Pituitary gland (mg\%) & $2.65 \pm 0.45$ & $2.65 \pm 0.49$ & $2.79 \pm 0.48$ & $2.32 \pm 0.29$ & $2.47 \pm 0.31$ \\
\hline
\end{tabular}

Values are mean \pm SD.

$* * p<0.01$.

group was $85.75 \pm 6.14 \mathrm{~mm} \mathrm{Hg}$, while in the control group the mean value was $58.08 \pm 4.60 \mathrm{~mm} \mathrm{Hg}(p<0.05)$.

Treatment with VigRX for 12 weeks significantly increased levels of testosterone compared to the control ( $p$ $<0.05$ ) (Table 5). Mean serum testosterone levels in the VigRX treated rats were $6.20 \pm 2.57 \mathrm{ng} / \mathrm{mL}$ after 12 weeks of treatment while mean levels in the control group were 3.66 $\pm 1.10 \mathrm{ng} / \mathrm{mL}$.

There were no significant differences in weight gained in the male rats treated with VigRX daily for 12 weeks compared to the control group (Table 4). VigRX had no effect on the weights of any organs measured, including the penis, testes, epididymis, seminal vesicles, prostate gland, liver, kidney, adrenal gland, spleen and pituitary glands. There were also no significant histopathological findings in either the control or treatment groups.

VigRX had no effect on any other blood chemistries or blood parameters measured, including those of glucose, BUN, creatinine, cholesterol, triglycerides, AST, ALT, alkaline phosphatase, total protein, or albumin, with the exception of a statistically significant decrease in lymphocytes found in the treatment group (Table 5). However, because no other clinically significant findings accompanied this result, including an absence of histopathological abnormalities, the decrease in lymphocytes may be an incidental finding and not related to the treatment article.

\section{DISCUSSION}

Two separate analyses from different labs determined that VigRX (Lot \# 4242) was not adulterated with any of the tested pharmaceutical ingredients, including drugs commonly used for the treatment of erectile dysfunction or their analogues. Performing these analyses on the end product is the best way to determine that no adulteration occurred during any step of the manufacturing process. Not only does this protect consumers from unexpected side-effects and druginteractions, it also assures that any treatment effects observed clinically are due to the product's stated formulation and not to unnamed and unlisted pharmaceutical agents.

While there are a number of dietary supplements on the market making claims about erectile function and sexual health, most have yet to be substantiated by scientific research performed on the end product.

The Rho-kinase assay can help reveal one of the potential mechanisms of action behind the efficacy of an erectile health product. In this study, VigRX was shown to have an $\mathrm{IC}_{50}$ of $1673.18 \mu \mathrm{g} / \mathrm{mL}$. While this result shows an inhibitory action against the Rho-kinase enzyme in vitro, the relatively high $\mathrm{IC}_{50}$ suggests that a large dose would be necessary to achieve similar results in a living system. This may imply that, while inhibition of the Rho-kinase enzyme is a possible partial explanation for the activity of VigRX, other mechanisms may also be at play. Future research into the effect of VigRX on other aspects of erectile health, such as the nitric oxide pathway, may help further explain its efficacy as observed in the rat.

The 14-day study revealed that the rats fed VigRX at the dosage of $30 \mathrm{mg} / \mathrm{kg} /$ day showed an increased sex drive as reflected by the increased frequency of every measured parameter, including mounting, intromission, and ejaculation frequencies, as well as short intromission and ejaculation latencies during the observed 30-minutes of sexual behavior. In addition to increased sex drive, VigRX treatment also increased the erect penile size, the intracavernosal pressure and sperm concentration, without affecting testosterone levels. One hypothesis for the increased sperm concentration is 
Table 5. Blood Parameters in Rat Studies

\begin{tabular}{|c|c|c|c|c|c|}
\hline & \multicolumn{3}{|c|}{$\begin{array}{c}\text { 2-week (14-day) study } \\
\text { n=10 per group }\end{array}$} & \multicolumn{2}{|c|}{$\begin{array}{l}\text { 12-week study } \\
\text { n=12 per group }\end{array}$} \\
\hline & Control & $\begin{array}{c}\text { VigRX } \\
15 \mathrm{mg} / \mathrm{kg} / \mathrm{day}\end{array}$ & $\begin{array}{c}\text { VigRX } \\
30 \mathrm{mg} / \mathrm{kg} / \mathrm{day}\end{array}$ & Control & $\begin{array}{c}\text { VigRX } \\
15 \mathrm{mg} / \mathrm{kg} / \mathrm{day}\end{array}$ \\
\hline Glucose (mg/dL) & $\mathrm{NP}$ & NP & NP & $126.92 \pm 25.89$ & $126.25 \pm 16.21$ \\
\hline Blood Urea Nitrogen (BUN) (mg/dL) & $\mathrm{NP}$ & $\mathrm{NP}$ & NP & $27.33 \pm 2.42$ & $27.58 \pm 2.50$ \\
\hline Creatine $(\mathrm{mg} / \mathrm{dL})$ & $\mathrm{NP}$ & $\mathrm{NP}$ & NP & $0.36 \pm 0.08$ & $0.39 \pm 0.08$ \\
\hline Cholesterol (mg/dL) & NP & NP & NP & $77.67 \pm 7.63$ & $71.58 \pm 7.69$ \\
\hline Triglyceride (mg/dL) & $\mathrm{NP}$ & $\mathrm{NP}$ & NP & $22.70 \pm 9.80$ & $20.57 \pm 14.76$ \\
\hline Aspartate aminotransferase (AST) (U/L) & $\mathrm{NP}$ & NP & NP & $85.90 \pm 26.51$ & $108.45 \pm 40.25$ \\
\hline Alanine Aminotransferase (ALT) (U/L) & NP & NP & NP & $59.90 \pm 19.16$ & $54.22 \pm 13.15$ \\
\hline Alkaline phosphatase (U/L) & $\mathrm{NP}$ & $\mathrm{NP}$ & NP & $89.00 \pm 15.85$ & $93.17 \pm 20.64$ \\
\hline Total protein & NP & $\mathrm{NP}$ & $\mathrm{NP}$ & $5.95 \pm 0.47$ & $5.73 \pm 0.23$ \\
\hline Albumin (g/dL) & $\mathrm{NP}$ & $\mathrm{NP}$ & NP & $3.75 \pm 0.13$ & $3.72 \pm 0.12$ \\
\hline White blood cell (cells $/ \mathrm{mm}^{3}$ ) & $\mathrm{NP}$ & $\mathrm{NP}$ & $\mathrm{NP}$ & $2436.36 \pm 490.45$ & $2522.22 \pm 618.02$ \\
\hline Hemoglobin (g/dL) & NP & $\mathrm{NP}$ & NP & $13.80 \pm 1.51$ & $14.42 \pm 0.42$ \\
\hline Hematocrit (\%) & NP & $\mathrm{NP}$ & NP & $42.43 \pm 4.78$ & $45.11 \pm 2.27$ \\
\hline Red blood cell (mill/ $\mu \mathrm{L})$ & NP & $\mathrm{NP}$ & NP & $7.92 \pm 0.85$ & $8.33 \pm 0.52$ \\
\hline Platelet (thsnd/ $\mu \mathrm{L}$ ) & NP & $\mathrm{NP}$ & NP & $652.17 \pm 78.17$ & $646.75 \pm 54.74$ \\
\hline Polymorphonuclear granular leucocyte (\%) & $\mathrm{NP}$ & $\mathrm{NP}$ & $\mathrm{NP}$ & $14.67 \pm 9.23$ & $22.20 \pm 8.92$ \\
\hline Lymphocytes $(\%)$ & NP & $\mathrm{NP}$ & NP & $83.58 \pm 9.44$ & $74.40 \pm 9.87 *$ \\
\hline Monocytes (\%) & $\mathrm{NP}$ & $\mathrm{NP}$ & $\mathrm{NP}$ & $3.00 \pm 0.00$ & $2.38 \pm 1.06$ \\
\hline Eosinophils (\%) & NP & $\mathrm{NP}$ & NP & $1.33 \pm 0.50$ & $2.50 \pm 1.22$ \\
\hline Mean corpuscular volume (fL) & $\mathrm{NP}$ & $\mathrm{NP}$ & $\mathrm{NP}$ & $53.50 \pm 0.52$ & $53.80 \pm 0.92$ \\
\hline Mean corpuscular hemoglobin (pg) & $\mathrm{NP}$ & $\mathrm{NP}$ & $\mathrm{NP}$ & $17.43 \pm 0.36$ & $17.23 \pm 0.65$ \\
\hline $\begin{array}{l}\text { Mean corpuscular hemoglobin concentra- } \\
\text { tion }(\%)\end{array}$ & $\mathrm{NP}$ & $\mathrm{NP}$ & NP & $32.37 \pm 0.32$ & $31.97 \pm 0.84$ \\
\hline Testosterone (ng/mL) & $5.79 \pm 2.15$ & $4.69 \pm 2.37$ & $5.51 \pm 2.18$ & $3.66 \pm 1.10$ & $6.20 \pm 2.57^{*}$ \\
\hline
\end{tabular}

Values are mean \pm SD.

$\mathrm{NP}=$ not performed

$* p<0.05$.

that VigRX treatment leads to an increased blood flow to the testes and consequently increases spermatogenesis. Herbs found in VigRX that have demonstrated the ability to increase circulation include hawthorn berry and ginkgo leaf $[15,16]$. However, no research has been published specifically on the effect of these herbs on testicular blood flow or spermatogenesis.

VigRX had no effect on the weights of the majority of organs measured in the 14-day study, with the exception of a statistically significant decrease in liver weight (both treatment groups) and kidney weight (15 mg/kg group only). The mechanisms by which VigRX could decrease the liver and kidney weight are still unknown. One possible explanation for the decrease in liver weight is that the increased mount- ing behavior, blood flow, and other demands of increased sex drive experienced by the rats treated with VigRX created an increased energy need, thus increasing the rate of glycogenolysis in the liver. Further investigation of this hypothesis is needed. However, the decrease in liver and kidney sizes were not found to be dose dependent. This, coupled with the relatively small number of test animals, makes it difficult to determine whether this finding was due to a treatment effect of VigRX or spontaneous findings in individual test animals.

Unlike the 14-day study, the 12-week study on VigRX found no significant effect on the sexual behavior of male rats. However, this study did corroborate the earlier findings of increased sperm concentration, width of erect penis (but not length), and intracavernosal pressure. Because the 12- 
week study only examined the effects of $15 \mathrm{mg} / \mathrm{kg} / \mathrm{day}$, while the 14-day study found $30 \mathrm{mg} / \mathrm{kg} /$ day to be the more effective dose, perhaps it is the lower dose that could account for the decreased treatment response in the 12-week study.

The 12-week study did not show the decreases in liver and kidney weights found in the 14-day study, and histopathological examination revealed no abnormalities in any organs. This may lend further credence to the hypothesis that the initial findings in the shorter study were sporadic and not treatment related.

Two significant hematological findings were noted in the 12-week study. The first was an increase in testosterone, which was not found in the 14-day study. While there were no concomitant increases in prostate or seminal vesicle weight, this finding warrants further investigation into the long-term effects of VigRX on prostate health. Recent longterm studies in humans have questioned whether elevated testosterone levels contribute to adverse prostate health or an increased risk of cancer, hence the clinical significance of elevated testosterone remains unknown [28,29]. A retrospective analysis of numerous studies found no causal relationship between testosterone replacement and prostate cancer or heart disease risk, nor did another study that reviewed decades of research find compelling evidence that higher than normal testosterone levels increased the risk of prostate cancer or cardiovascular disease [28,29].

The second statistically significant hematological finding was a decrease in lymphocyte production. However, because no other clinically significant findings accompanied this result, including histopathological abnormalities, the decrease in lymphocytes may be an incidental finding, not related to the treatment article. No other blood parameter measured differed significantly from control.

\section{CONCLUSION}

Overall this research provides scientific evidence in support of the purity, safety, and potential efficacy of this herbal formulation in supporting male sexual health. Inhibition of the enzyme Rho-kinase, and increases in serum testosterone are two possible mechanisms of action for this formula. It is likely that additional mechanisms play a role in the efficacy as seen in the 14-day and 12-week rat studies, which require further investigation. Research exploring other physiological effects, as well as human clinical trials, are needed to better understand the role VigRX may play in supporting and/or enhancing male sexual function. Additional in vivo toxicology studies would be beneficial to more fully evaluate the safety of long-term consumption of this product.

\section{CONFLICT OF INTEREST STATEMENT}

AIBMR Life Sciences, Inc. was hired as an independent consulting agency to design and implement studies on VigRX. None of the authors have any financial interest in the product.

\section{ABBREVIATIONS}

$\begin{array}{ll}\mu \mathrm{L} & =\text { microliter } \\ \mu \mathrm{m} & =\text { micrometer }\end{array}$

ANOVA $=$ analysis of variance

$\begin{array}{ll}\text { APIs } & =\text { active pharmaceutical ingredients } \\ \text { ALT } & =\text { alanine aminotransferase } \\ \text { AST } & =\text { aspartate aminotransferase } \\ \text { ATP } & =\text { adenosine triphosphate } \\ \text { BUN } & =\text { blood urea nitrogen } \\ \text { CNS } & =\text { central nervous system } \\ \text { eNOS } & =\text { endothelial nitric-oxide synthase } \\ \text { ELISA } & =\text { enzyme-linked-immunosorbent } \\ \text { ESI } & =\text { electrologic } \\ \text { g } & =\text { gram } \\ \text { HPLC } & =\text { high performance liquid chromatography } \\ \text { HPLC- } & =\text { high performance liquid chromatography- } \\ \text { PDA-MSn } & \text { photodiode array-mass spectrometry } \\ \text { HRP } & =\text { horseradish peroxidase } \\ \text { IC } & =\text { po }\end{array}$

\section{REFERENCES}

[1] Lewis, R.W.; Fugl-Meyer, K.S.; Bosch, R.; Fugl-Meyer, A.R.; Laumann, E.O.; Lizza, E.; Martin-Morales, A. Epidemiology/risk factors of sexual dysfunction. J. Sex Med., 2004, 1(1), 35-39.

[2] Laumann, E.O.; Paik, A.; Rosen, R.C. Sexual dysfunction in the United States: prevalence and predictors. JAMA, 1999, 281(6), 53744.

[3] Dean, R.C.; Lue, T.F. Physiology of penile erection and pathophysiology of erectile dysfunction. Urol. Clin. North Am., 2005, 32(4), 379-95, v.

[4] Vlachopoulos, C.; Aznaouridis, K.; Ioakeimidis, N.; Rokkas, K.; Vasiliadou, C.; Alexopoulos, N.; Stefanadi, E.; Askitis, A.; Stefanadis, C. Unfavorable endothelial and inflammatory state in erectile dysfunction patients with or without coronary artery disease. 
Eur. Heart J., 2006, 27(22), 2640-8.

[5] Jin, L.; Liu, T.; Lagoda, G.A.; Champion, H.C.; Bivalacqua, T.J.; Burnett, A.L. Elevated RhoA/Rho-kinase activity in the aged rat penis: mechanism for age-associated erectile dysfunction. FASEB J., 2006, 20(3), 536-8.

[6] Haas, C.A.; Seftel, A.D.; Razmjouei, K.; Ganz, M.B.; Hampel, N.; Ferguson, K. Erectile dysfunction in aging: upregulation of endothelial nitric oxide synthase. Urology, 1998, 51(3), 516-22.

[7] United States Food and Drug Administration, FDA News. FDA Warns Consumers Not to Use Super Shangai, Strong Testis, Shangai Ultra, Shangai Ultra X, Lady Shangai, and Shangai Regular (also known as Shangai Chaojimengnan). http://www.fda.gov/bbs/ topics/NEWS/2007/NEW01766.html (accessed 13 November 2008).

[8] Sunwoo, S.; Kim, Y.S.; Cho, B.L.; Cheon, K.S.; Seo, H.G.; Rho, M.K.; Cheong, Y.S.; Hong, M.H.; Kim, S.W.; Kim, D.H. Postmarketing surveillance study of the safety and efficacy of sildenafil prescribed in primary care to erectile dysfunction patients. Int. J. Impot. Res., 2005, 17(1), 71-5.

[9] Fink, H.A.; Mac Donald, R.; Rutks, I.R.; Nelson, D.B.; Wilt, T.J. Sildenafil for male erectile dysfunction: a systematic review and meta-analysis. Arch. Intern. Med., 2002, 162(12), 1349-60.

[10] Langtry, H.D.; Markham, A. Sildenafil: a review of its use in erectile dysfunction. Drugs, 1999, 57(6), 967-89.

[11] United States Food and Drug Administration, FDA News. FDA Warns Consumers About Dangerous Ingredients in "Dietary Supplements" Promoted for Sexual Enhancement. http://www.fda.gov/bbs/topics/NEWS/2006/NEW01409.html (accessed 13 November 2008).

[12] United States Food and Drug Administration, FDA News. Hidden risks of erectile dysfunction "treatments" sold online. http://www.fda.gov/bbs/topics/news/2007/NEW01737.html (accessed 13 November 2008).

[13] Antunes, E.; Gordo, W. M.; de Oliveira, J. F.; Teixeira, C. E.; Hyslop, S.; De Nucci, G. The relaxation of isolated rabbit corpus cavernosum by the herbal medicine Catuama and its constituents. Phytother. Res., 2001, 15(5), 416-21.

[14] Yeh, K.Y.; Pu, H.F.; Kaphle, K.; Lin, S.F.; Wu, L.S.; Lin, J.H.; Tsai, Y.F. Ginkgo biloba extract enhances male copulatory behavior and reduces serum prolactin levels in rats. Horm. Behav., 2008, 53(1), 225-31.

[15] McKay, D. Nutrients and botanicals for erectile dysfunction: examining the evidence. Altern. Med. Rev., 2004, 9(1), 4-16.

[16] McKenna, D.J.; Jones, K.; Hughes, K.; Humphrey, S. Botanical Medicines: The Desk Reference for Major Herbal Supplements, $2^{\text {nd }}$ ed. The Haworth Herbal Press: New York, 2002, pp. 657-76.
[17] Vierling, W.; Brand, N.; Gaedcke, F.; Sensch, K.H.; Schneider, E.; Scholz, M. Investigation of the pharmaceutical and pharmacological equivalence of different Hawthorn extracts. Phytomedicine, 2003, 10(1), 8-16.

[18] Steers, W.D. Pharmacologic treatment of erectile dysfunction. Rev. Urol., 2002, 4 (Suppl 3), S17-25.

[19] Rajasekaran, M.; White, S.; Baquir, A.; Wilkes, N. Rho-kinase inhibition improves erectile function in aging male Brown-Norway rats. J. Androl., 2005, 26(2), 182-8.

[20] Quinlan, D.M.; Nelson, R.J.; Partin, A.W.; Mostwin, J.L.; Walsh, P.C. The rat as a model for the study of penile erection. J. Urol., 1989, 141(3), 656-61.

[21] Ang, H.H.; Ngai, T.H. Aphrodisiac evaluation in non-copulator male rats after chronic administration of Eurycoma longifolia Jack. Fundam. Clin. Pharmacol., 2001, 15(4), 265-8.

[22] Carro-Juarez, M.; Cervantes, E.; Cervantes-Mendez, M.; Rodriguez-Manzo, G. Aphrodisiac properties of Montanoa tomentosa aqueous crude extract in male rats. Pharmacol. Biochem. Behav., 2004, 78(1), 129-34.

[23] Gauthaman, K.; Adaikan, P.G. Effect of Tribulus terrestris on nicotinamide adenine dinucleotide phosphate-diaphorase activity and androgen receptors in rat brain. J. Ethnopharmacol., 2005, 96(1-2), 127-32.

[24] Ramachandran, S.; Sridhar, Y.; Sam, S.K.; Saravanan, M.; Leonard, J.T.; Anbalagan, N.; Sridhar, S.K. Aphrodisiac activity of Butea frondosa Koen. ex Roxb. extract in male rats. Phytomedicine, 2004, 11(2-3), 165-8.

[25] Tajuddin, Ahmad, S.; Latif, A.; Qasmi, I. A. Effect of 50\% ethanolic extract of Syzygium aromaticum (L.) Merr. \& Perry. (clove) on sexual behavior of normal male rats. BMC Complement. Altern.Med., 2004, 4(1), 17.

[26] Islam, M.W.; Tariq, M.; Ageel, A.M.; al-Said, M.S.; al-Yhya, A.M. Effect of Salvia haematodes on sexual behaviour of male rats. J. Ethnopharmacol., 1991, 33(1-2), 67-72.

[27] Tocharus, C.; Smitasiri, Y.; Jeenapongsa, R. Butea superba Roxb. enhances penile erection in rats. Phytother. Res., 2006, 20(6), 4849.

[28] Rhoden, E.L.; Morgentaler, A. Risks of testosterone-replacement therapy and recommendations for monitoring. N. Engl. J. Med., 2004, 350(5), 482-92.

[29] Endogenous hormones and prostate cancer collaborative group. Endogenous sex hormones and prostate cancer: A collaborative analysis of 18 prospective studies. J. Natl. Cancer Inst., 2008 , $100(3), 170-83$. 